\title{
Originals
}

\section{Biochemical and morpho-cytochemical evidence for the intestinal absorption of insulin in control and diabetic rats. Comparison between the effectiveness of duodenal and colon mucosa}

\author{
M.Bendayan ${ }^{1}$, E.Ziv ${ }^{1,2}$, D. Gingras ${ }^{1}$, R. Ben-Sasson ${ }^{2}$, H. Bar-On ${ }^{2}$, M. Kidron ${ }^{2}$ \\ ${ }^{1}$ Department of Anatomy, Université de Montréal, Montréal, Québec, Canada \\ ${ }^{2}$ Department of Medicine, Hadassah University Hospital, The Hebrew University, Jerusalem, Israel
}

\begin{abstract}
Summary A combined biochemical and morpho-cytochemical investigation was carried out in order to assess insulin absorption by the duodenal and colon epithelium. Insulin was introduced in the lumen of the rat duodenum or colon in combination with sodium cholate and aprotinin. Blood analysis made at several time points has demonstrated a rapid increase in circulating levels of insulin followed by significant and consistent decreases in blood glucose. This indicates that biologically active insulin is absorbed by the intestinal mucosa and transferred to the circulation. Because of the initial high blood glucose levels, the lowering of the glycaemic values was more significant in diabetic animals. Also, levels of circulating insulin remained higher for longer time when the administration was performed in the colon. The integrity of the intestinal wall after insulin administration, evaluated morphologically, was retained. Application of protein A-gold immunocytochemistry has established the pathway for insulin ab-
\end{abstract}

sorption. In both duodenal and colon epithelial cells the labelling for insulin was detected in the endosomal compartment, in the Golgi apparatus and in association with the baso-lateral plasma membrane interdigitations. Some labelling was also present in the interstitial space and in capillary endothelial plasmalemmal vesicles. Insulin introduced in the lumen of the rat duodenum and colon appears thus to be rapidly internalized by the epithelial cells and transferred through a transcytotic pathway to the interstitial space from which it reaches the blood circulation. This exogenous insulin then induces significant decreases in plasma glucose levels which lasts for several hours. The results obtained support the possibility for the clinical development of an oral preparation of insulin. [Diabetologia (1994) 37:119-126]

Key words Insulin absorption, oral insulin, immunocytochemistry, diabetes mellitus.
Numerous efforts have been made in the last ten years in order to establish alternative methods to the injection of insulin in the treatment of diabetes. Among the different attempts, nasal [1-3], rectal [4-8] and oral [916] routes for insulin administration have been assessed with significant and promising results. Among the three routes, oral administration appears to be the more convenient, appropriate and certainly the most physiological, insulin being directly channelled from

Received: 12 October 1992

and in revised form: 10 August 1993

Corresponding author: Dr. M.Bendayan, Department of Anatomy, Université de Montréal, C.P.6128, Succ. "A", Montréal, Québec, Canada H3C 3J7 the intestine to the liver. Since the discovery of insulin attempts at oral administration have been made with differing amounts of effectiveness [17-21]. This is due to problems with the fact that insulin administered orally encounters the proteolytic activity of the gastrointestinal tract and the relative impermeability of the intestinal epithelium to the transport of peptides. Previous studies $[6,12,15]$ have established conditions which allow for the relative protection of the peptide against intestinal degradation and for the stimulation of its absorption. Along this line, in our previous in situ work on small restrained isolated segments of rat ileum, we have demonstrated that insulin under certain conditions, is absorbed by the ileal epithelium and transferred to the blood circulation [15]. 
The ultimate aim of the study on oral delivery of insulin is to establish an insulin tablet for the treatment of diabetic patients. The disintegration of this tablet may take place in different portions of the intestine. Therefore, it is important to establish by different means, the efficiency of insulin absorption in different segments of the intestine [11]. In the present study, we have investigated the absorption of insulin by the duodenal and the colon segments of the intestine. In addition the study was performed on control and diabetic rats, monitoring their blood glucose levels for several hours after enteral administration of insulin. Since the integrity of the intestinal wall is of critical concern, we have examined by various morphological means the state of the epithelium as well as of the epithelial cell membrane and intercellular junctions after short and long exposure to the insulin solution. By applying the immunocytochemical protein A-gold technique [22, 23], we were also able to establish the pathway of internalization of insulin by the enterocytes in both the duodenal and colon sites, allowing for a better understanding of the transcytotic mechanism taking place through the epithelial cells.

\section{Materials and methods}

\section{Animals}

Sprague Dawley male rats (Charles River Canada, St-Constant, Quebec, Canada) weighing 100-150 g, were used in the present study. They were kept on a standard diet and had free access to food and water. Diabetes was induced in fasted animals by intraperitoneal injection of streptozotocin $(50-70 \mathrm{mg} / \mathrm{kg}$ body weight, in citrate buffer $10 \mathrm{mmol} / / \mathrm{pH} 4.5$ ). The animals had high blood glucose values with strong glycosuria $24-\mathrm{h}$ post-injection. They remained hyperglycaemic until the time of the experiment about 3 months after the streptozotocin administration, as monitored by regular measurements of the glycosuria (Multistix reagent strips; Miles, Ames, Ontario, Canada). The hyperglycaemic animals did not receive any insulin treatment during these 3 months. Prior to the experiment, the animals were fasted for $12 \mathrm{~h}$. Control and diabetic animals were anaesthetized by intraperitoneal injection of urethane $(0.75 \mathrm{mg} / \mathrm{kg})$. A small longitudinal incision of the abdomen was made and a loop of the duodenum or of the ascending portion of the colon was exposed in order to insert the insulin solution. A $1 \mathrm{ml}$ solution of $0.15 \mathrm{~mol} / \mathrm{l} \mathrm{NaCl}$ containing $200 \mathrm{IU}$ of human insulin (Connaught Novo, Lachine, Quebec, Canada), $2500 \mathrm{KIU}$ (kallikrein inhibitor units) of aprotinin (Trasylol, Bayer, Leverkusen, Germany) and $10 \mathrm{mg}$ of sodium cholate (Sigma, St Louis, Mo., USA) was inserted into the lumen of the duodenom or of the colon. The abdominal wall was then resealed and the animal maintained under anaesthesia for the following $6 \mathrm{~h}$. The animals did not recover from the experiment.

\section{Blood analysis}

Plasma glucose and insulin levels were monitored by multiple samplings. Glucose determination was performed by Glucostix using a Glucometer (Miles, Ames) on drops of blood sampled from the caudal artery, while insulin was determined by radioimmunoassay on blood samples from the carotid arteries. For the radioimmunoassay of insulin a commercial kit was used (RIA Kit; Chromacod, Biomega, Montreal, Quebec, Canada) on samples diluted $1 / 10$ to $1 / 50$. Sampling and analysis of blood glucose and insulin levels were done 30 and $60 \mathrm{~min}$ after the administration of insulin and then at 60-min intervals. Because of difficulties in performing repetitious blood sampling in the carotid arteries, insulin levels were determined at least during the first $2 \mathrm{~h}$.

\section{Morphological study}

At the end of the 6-h experiment, the intestinal tissue was sampled within $10 \mathrm{~mm}$ down stream from the site of insertion, in order to evaluate by morphological means the state of the tissue and the integrity of the wall exposed to the insulin solution. The tissues were fixed with $1 \%$ glutaraldehyde, post-fixed with $1 \%$ osmium tetroxide and embedded in Epon. Semi-thin sections were performed, stained with toluidine blue and observed by light microscopy. Thin sections stained with uranyl acetate lead citrate were examined with a Philip 410SL electron microscope. In addition glutaraldehyde-fixed tissues were processed for the production of freeze-fracture replicas according to routine techniques [24].

\section{Immunocytochemical study}

For the immunocytochemical study, the same experimental protocol was followed on different animals. However, in these cases the duodenal or colon tissues were sampled 2, 5, 10 and $30 \mathrm{~min}$ after insulin administration. The tissues were immediately fixed by immersion in a $1 \%$ glutaraldehyde, $0.1 \mathrm{~mol} / \mathrm{l}$ phosphate buffer solution for $2 \mathrm{~h}$ at room temperature, post-fixed with $1 \%$ osmium tetroxide, dehydrated in graded ethanol solutions and embedded in Epon. Insulin was detected by applying the protein A-gold technique $[22,23]$ in combination with a specific anti-insulin antibody as described previously [15]. The thin sections of duodenum or colon were mounted on nickel grids and incubated for $1 \mathrm{~h}$ with a saturated aqueous solution of sodium metaperiodate. This was followed by a 2 -h incubation with the anti-insulin antibody (1/200 dilution) and a 30-min incubation with the protein A-gold complex. The protein A-gold complex was prepared as described previously with $15 \mathrm{~nm}$ gold particles [25]. Tissues from control and diabetic animals were processed in parallel. In addition and in order to assess the specificity of the labellings obtained, cytochemical control experiments were performed, in particular the use of insulin-adsorbed antibody prior to the incubation with the protein A-gold complex, the omission of the antibody in the labelling protocol and the use of anti-insulin/protein A-gold labelling on intestinal tissue of animals not injected with insulin.

\section{Statistical analysis}

Mean values were calculated for each time point and are reported with their corresponding standard deviation.

\section{Results}

The biochemical determinations of plasma glucose and insulin levels at different time points after the insertion of insulin into the lumen of the rat duodenum or colon 
Table 1. Plasma glucose and insulin levels in normal and diabetic rats at different time points after the introduction of the insulin solution into the duodenum

\begin{tabular}{|c|c|c|c|c|}
\hline \multirow[t]{2}{*}{ Time (min) } & \multicolumn{2}{|c|}{ Plasma glucose levels $(\mathrm{mmol} / \mathrm{l})$} & \multicolumn{2}{|c|}{ Plasma insulin levels (pmol/l) } \\
\hline & $\begin{array}{l}\text { Normal rats } \\
(n=5)\end{array}$ & $\begin{array}{l}\text { Diabetic rats } \\
(n=9)\end{array}$ & $\begin{array}{l}\text { Normal rats } \\
(n=5)\end{array}$ & $\begin{array}{l}\text { Diabetic rats } \\
(n=9)\end{array}$ \\
\hline 0 & $3.9 \pm 0.6$ & $26.8 \pm 1.4$ & $168 \pm 55$ & $109 \pm 18$ \\
\hline 30 & $2.3 \pm 0.2$ & $21.6 \pm 1.2$ & $578 \pm 170$ & $1760 \pm 730$ \\
\hline 60 & $1.4 \pm 0.4$ & $18.7 \pm 1.6$ & $225 \pm 17$ & $1260 \pm 500$ \\
\hline 120 & $1.1 \pm 0.6$ & $15.6 \pm 2.0$ & $142 \pm 33$ & $585 \pm 200$ \\
\hline 180 & $0.9 \pm 0.7$ & $12.0 \pm 2.9$ & & $460 \pm 80$ \\
\hline 240 & $1.2 \pm 1.1$ & $11.2 \pm 2.1$ & & $240 \pm 70$ \\
\hline 300 & - & $11.0 \pm 2.8$ & & \\
\hline 360 & $2.2(n=2)$ & $8.0 \pm 1.2$ & & \\
\hline
\end{tabular}

Table 2. Plasma glucose and insulin levels in normal and diabetic rats at different time points after the introduction of the insulin solution into the colon

\begin{tabular}{|c|c|c|c|c|}
\hline \multirow[t]{2}{*}{ Time $(\min )$} & \multicolumn{2}{|c|}{ Plasma glucose levels (mmol/l) } & \multicolumn{2}{|c|}{ Plasma insulin levels (pmol/l) } \\
\hline & $\begin{array}{l}\text { Normal rats } \\
(n=5)\end{array}$ & $\begin{array}{l}\text { Diabetic rats } \\
(n=7)\end{array}$ & $\begin{array}{l}\text { Normal rats } \\
(n=5)\end{array}$ & $\begin{array}{l}\text { Diabetic rats } \\
(n=7)\end{array}$ \\
\hline 0 & $3.4 \pm 0.4$ & $25.9 \pm 2.9$ & $41 \pm 12$ & $33 \pm 1.5$ \\
\hline 30 & $1.5 \pm 0.5$ & $21.2 \pm 2.7$ & $1280 \pm 320$ & $1570 \pm 600$ \\
\hline 60 & $1.0 \pm 0.3$ & $20.4 \pm 2.1$ & $1090 \pm 260$ & $1480 \pm 720$ \\
\hline 120 & $0.7 \pm 0.4$ & $16.1 \pm 2.7$ & $820 \pm 350$ & $1415 \pm 670$ \\
\hline 180 & $0.4 \pm 0.1$ & $15.8 \pm 3.4$ & $560 \pm 200$ & $728 \pm 360$ \\
\hline 240 & $0.2 \pm 0.1$ & $14.5 \pm 2.6$ & & \\
\hline 300 & $0.4 \pm 0.3$ & - & & \\
\hline 360 & - & $12.7 \pm 1.7$ & & \\
\hline
\end{tabular}

indicate that insulin does cross the intestinal wall and reach the blood circulation. Indeed, in normal as well as in diabetic animals, circulating levels of insulin rose significantly $30 \mathrm{~min}$ after insulin administration, the levels being important and consistent in all the experiments performed (Tables 1 and 2). The rise in circulating insulin was followed by a significant decrease in blood glucose levels (Tables 1 and 2). While in general the increase in insulin levels was transient, the drop in blood glucose levels lasted for several hours. Although the results were consistent, fluctuations in amplitude and length of the responses were recorded among the animals. This is reflected in the data presented in Tables 1 and 2 by the large standard deviations associated with some of the values. The diabetic animals with initially very high levels of glycaemia showed a significant decrease in their blood glucose and maintained low glucose levels for several hours after the insulin administration. No difference in the pattern of response was detected between normoglycaemic and hyperglycaemic animals (Tables 1 and 2). However, levels of circulating insulin remained high for longer periods when insulin was administered into the colon (Tables 1 and 2).

At the end of the 6-h experiment, the intestinal tissues were sampled and examined by morphological means. The integrity of the epithelial wall of the duodenum (Fig. 1) and colon (Fig. 2), as demonstrated by light (Figs. 1 and 2) and electron (Fig. 3) microscopy, was maintained with no detectable injury. The cells presented little evidence of stress, cellular damage or degeneration of membrane. They remained intact with well-developed microvilli and sealed junctional complexes. Freeze fracture replica of the apical and lateral plasma membranes of the enterocytes (Fig. 3) demonstrates the integrity of the structures as well as that of the tight junctions.

Application of the protein A-gold immunocytochemical technique on thin sections of the duodenal and colon tissues of insulin-treated animals, revealed insulin antigenic sites at different locations of the intestinal epithelium depending on the time point under study. Indeed, only 2 min after insulin administration, labelling was detected in dense material present in some regions of the intestinal lumen, particularly at the level of the tip of the villi and crypts (Fig. 4). Luminal regions located deep down the crypts were generally devoid of labelling. In parallel, epithelial cells located high in the villi were labelled by gold particles. In such cases the labelling was detected associated with the microvilli and the apical plasma membrane (Figs. 4 and 5). Occasionally some particles were also found associated with the lateral plasma membrane interdigitations (Fig.5). Intracellularly, in the apical region of the cell, most of the particles were located over or closely associated with endocytotic vesicles (Figs. 4 and 5); these 

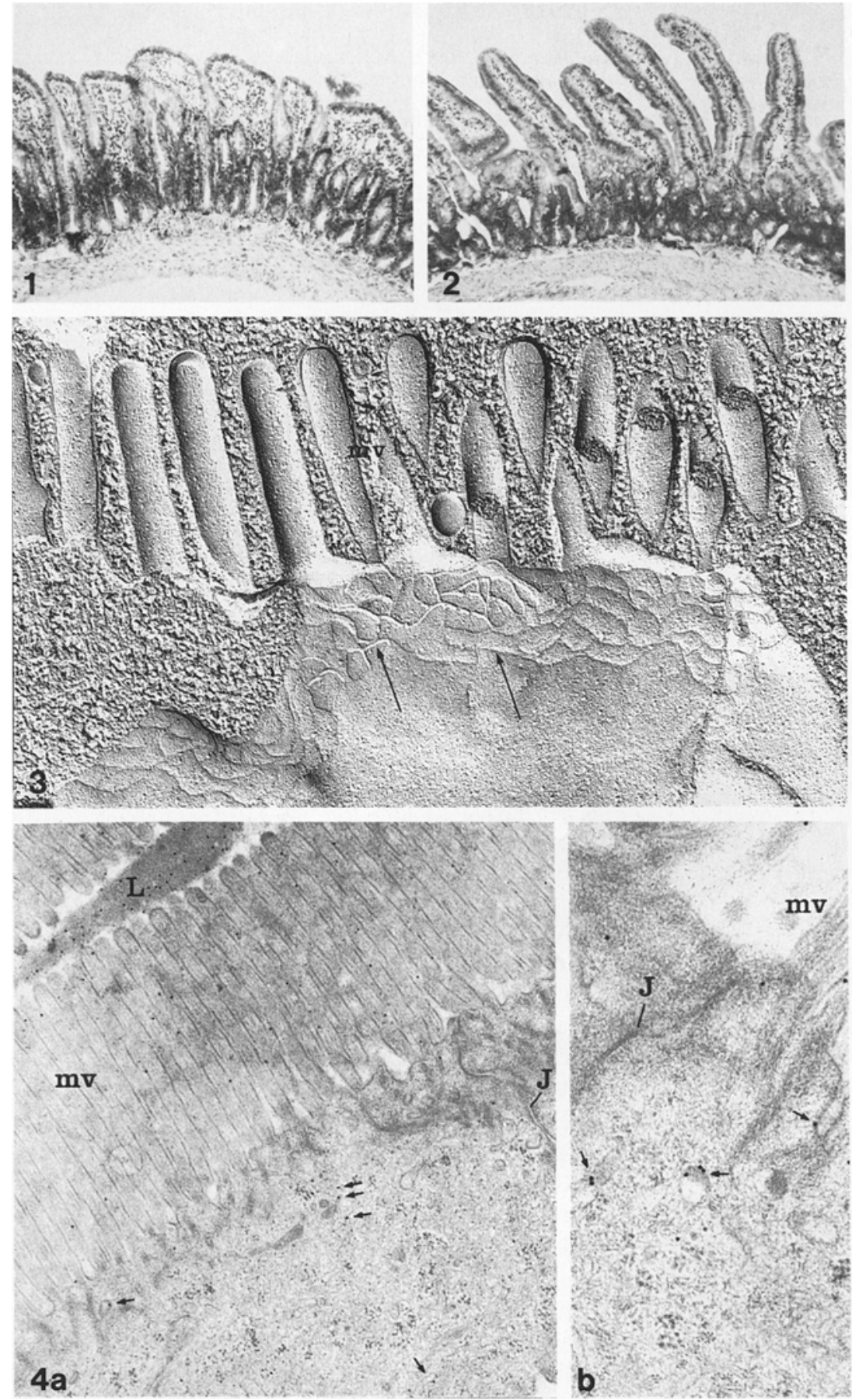

Fig.1. Light microscopy of duodenal tissue exposed for $6 \mathrm{~h}$ to the insulin solution. The integrity of the intestinal wall is evident. $\times 50$

Fig.2. Light microscopy of colon tissue exposed for $6 \mathrm{~h}$ to the insulin solution. Again the integrity of the wall is maintained. $\times 50$

Fig.3. Freeze-fracture replica illustrating the apical membrane with its microvilli (mv) and the lateral membrane with the tight junctions (arrows) of an enterocyte. The membrane leaflets appear normal with their intramembrane particles. Similarly the tight junction shows the typical ridges of intramembrane particles forming sealing strands (arrows). $\times 15,000$

Fig. 4 a,b. Rat duodenal tissue from a diabetic (a) and a normal rat (b), 2 (a) and 10 (b) min after the introduction of insulin in the duodenal lumen. Immunocytochemical detection of insulin by the protein A-gold technique.

Labelling by gold particles, revealing insulin antigenic sites is present in the dense content of the duodenal lumen (L), is associated with the plasma membrane of the microvilli (mv), with the invaginations of the apical plasma membrane and with the endocytotic vesicles (arrows). The junctional complexes (J) between epithelial cells are devoid of labelling a $\times 20,000$

b $\times 55,000$ were either open (Fig. 4b) into the luminal space as deep invaginations or closed (Figs. 4 and 5), forming part of the endosomal compartment. The morphological features of this endosomal compartment differed between duodenal (Fig.4) and colon (Fig.5) enterocytes. In the duodenal epithelial cells, the microvilli were numerous and tightly associated, the luminal invaginations and endocytotic vesicles were rather small, elongated and presented an electron dense content (Fig. 4). On the other hand, in the colon epithelial cells, the microvilli were shorter and less numerous, vesicles were more abundant, larger, electron lucent and more spherical than those of the duodenal cells (Fig. 5). In both tissues, the junctional complexes as well as the apical portion of the intercellular clefts were devoid of labelling. At $5 \mathrm{~min}$, the pattern of labelling was similar to that found at $2 \mathrm{~min}$ with a more significant labelling at the level of the lateral plasma membrane interdigitations. By $10 \mathrm{~min}$ (Figs. 6-8), the intracellular labelling was found deeper inside the cell and the Golgi apparatus displayed a certain number of gold particles (Fig. 6). These were located in the cisternae as well as in the 

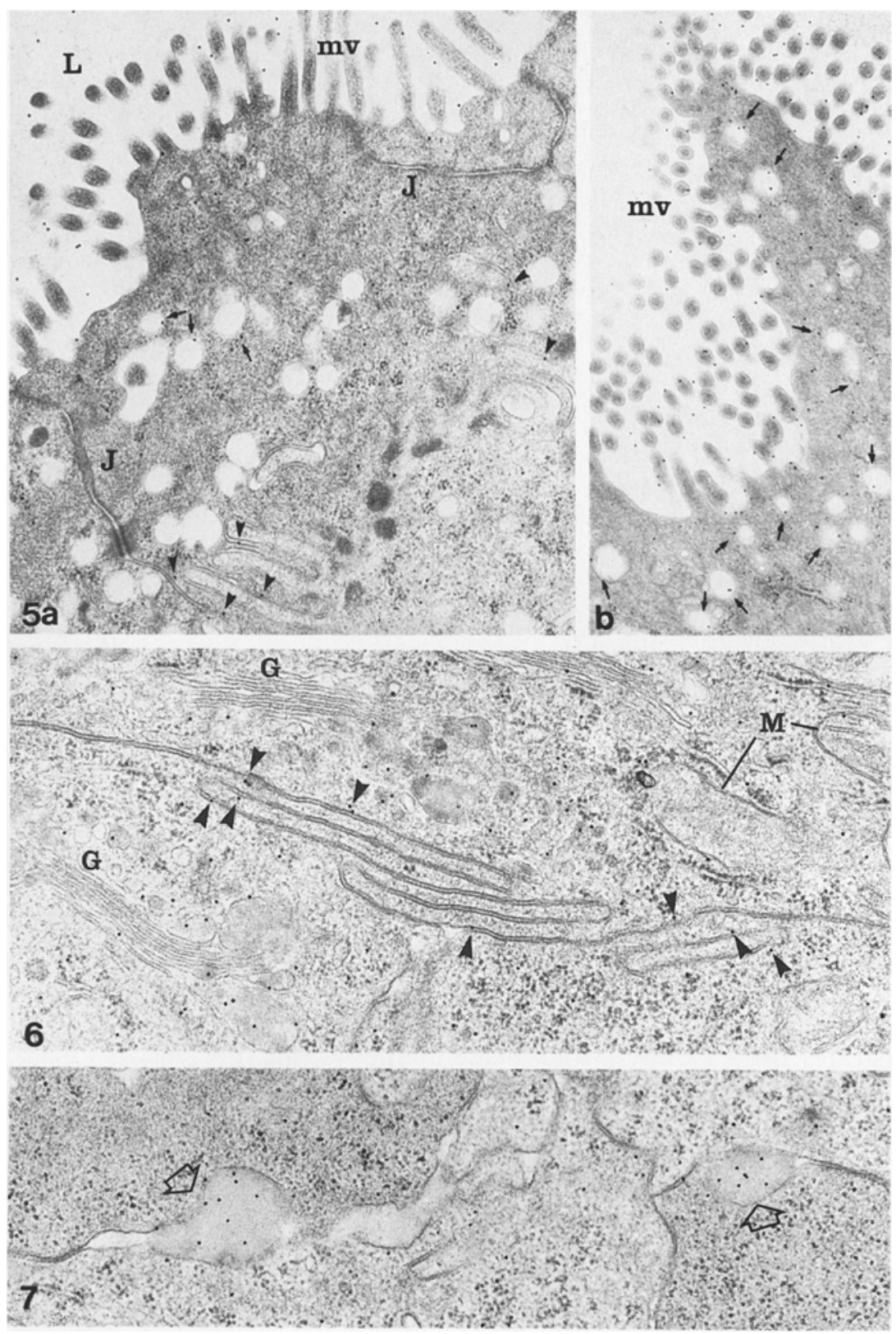

Fig. 5 a,b. Rat colon tissue from a diabetic animal 5 min after introduction of insulin in the lumen (L) of the colon. In (a) the junctional complexes $(\mathrm{J})$ at the apical portion of the cells are devoid of labelling while the lateral plasma membranes at the level of the interdigitations demonstrate some labelling (arrowheads). Few gold particles are found in the cytoplasm, they are either associated with small poorly-defined vesicles or constitute background staining. In (b) the labelling by gold particles is clearly associated with the plasma membrane of the microvilli ( $\mathrm{mv}$ ) and in endocytotic vesicles (arrows). $\times 25,000$

Fig. 6. Duodenal tissue from a diabetic animal 5 min after introduction of insulin in the duodenal lumen. Labelling for insulin is found in the Golgi region (G) particularly associated with golgian vesicles. Labelling is also associated with the lateral membranes (arrowheads). Very few gold particles which reflect background staining are seen over the mitochondria (M). $\times 40,000$

Fig. 7. Duodenal tissue from a diabetic animal 5 min after introduction of insulin in the duodenal lumen. Labelling for insulin is found in pocket-like structures (large arrows) delineated by the lateral membranes of neighbouring cells. $\times 45,000$ numerous golgian vesicles. Regarding other intracellular compartments, very few gold particles were detected in mitochondria (Figs. 6-8), lysosomes (Fig. 9) or nuclei. Because of their low number and their presence in control experiments, they were considered as background. In the extracellular space, the labelling was clearly associated with the lateral membranes (Figs. 79). In the duodenum, large intercellular pockets, delineated by neighbouring epithelial cells lateral plasma membranes and displaying an electron dense material, were significantly labelled by gold particles (Fig. 7). In the basal part of the cell (Fig. 8), the labelling was also associated with the plasma membrane which at this level forms large digitations enhancing the membrane surface and contact areas. Labelling although weak, was found in the interstitial space and in the capillary lumina (Fig. 8). Occasionally some gold particles were present in the endothelial cells associated with plasmalemmal vesicles (Fig. 8). In all tissues exposed to insulin, the labelling was restricted to the enterocytes. The mucous secreting cells (Fig. 9) and other non-epithelial cells such as the plasma cells were not specifically labelled. Only very few gold particles were present reflecting background staining (Fig.9). This supports the specificity of the cytochemical results and further indicates that the internalization of insulin takes place through enterocytes and not through mucous-secreting cells.

In the control experiments performed to assess the specificity of the cytochemical results, namely the labelling of intestinal tissue not exposed to insulin, the use of insulin-adsorbed anti-insulin as well as the incu- 


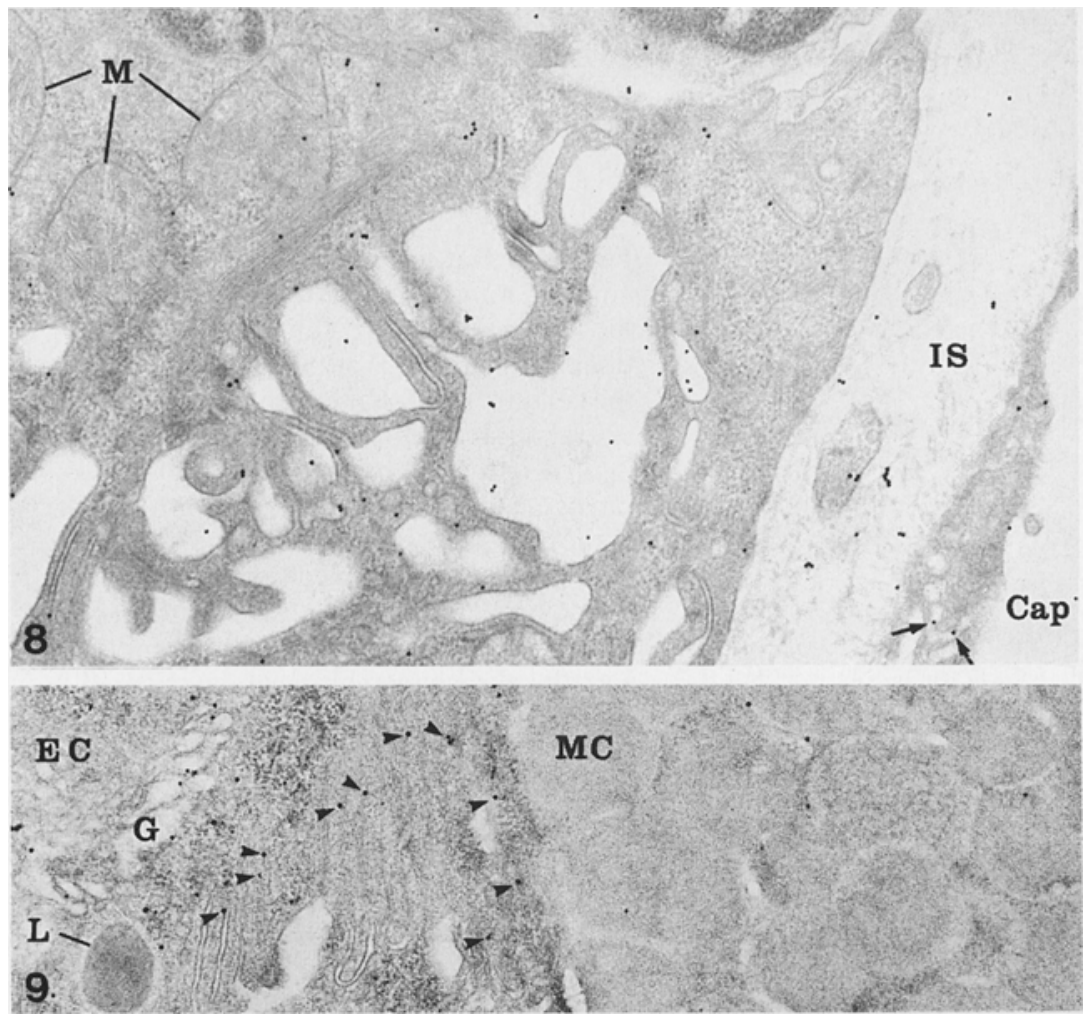

Fig.8. Duodenal tissue from a normal animal 10 min after introduction of insulin into the duodenal lumen. The figure illustrates the basal part of the cell. The labelling for insulin is associated with the basal plasma membrane which displays large invaginations. Some labelling is also present in the interstitial space (IS). Endothelial plasmalemmal vesicles are also labelled (arrows). Mitochondria (M) display some background staining. Cap, capillary. $\times 38,000$

Fig.9. Duodenal tissue from a normal animal $10 \mathrm{~min}$ after introduction of insulin into the duodenal lumen. The figure illustrates part of an enterocyte (EC) and of a mucous cell (MC). The labelling is almost restricted to the enterocyte particularly in the Golgi (G) and lateral plasma membrane (arrowheads). Very few gold particles (background staining) are found in the mucous cell. $\mathrm{L}$, lysosome. $\times 45,000$

bation with protein A-gold without an antibody, the labelling found over enterocytes was significantly reduced (results not illustrated). It was restricted to the presence of occasional gold particles randomly dispersed over the tissue. This result demonstrates the specificity of the labelling described for the experimental tissues.

\section{Discussion}

In the present study, we have investigated the absorption of insulin by the duodenal and the colon epithelia upon its introduction into the intestinal lumen. In contrast to a previous study [15], we have maintained the digestive tract intact, introducing the insulin into either the duodenum or the colon without restraining their length nor their biological activity and function. The experimental conditions were thus more physiological and better mimic the normal condition of an oral administration of insulin. The results obtained have demonstrated that upon introduction into the intestinal lumen, insulin is indeed absorbed by the epithelial cells and transferred to the blood circulation in which we rapidly detected very high levels. In turn, these have induced significant decreases in blood glucose levels. Placebo experiments [15] have clearly demonstrated that the decrease in blood glucose is the result of insulin absorption and that absence or variations in insulin concentrations yield no or slight changes in blood glucose levels. The efficiency of the absorption does not seem to differ significantly between the duodenum and the colon, although higher levels of circulating insulin remained for longer periods of time (up to $3 \mathrm{~h}$ ) when insulin was introduced in the colon. This may be interpreted that insulin, due to the presence of large amounts of digestive enzymes in the duodenum, is degraded more rapidly thus displaying a shorter half-life at this site. It also indicates that insulin absorption by the colon is quite significant in agreement with our previous results on rectal administration of insulin to human volunteers [8].

A definite heterogeneity was registered among the responses. This represents a common phenomenon, reported in most of the studies on oral administration of insulin $[18,19,21,26]$, probably due to conditions of the digestive tract and its content which could impair both rapid diffusion of the insulin as well as access to enterocyte membranes. Previous studies have defined conditions for protecting peptides from complete degradation in the intestinal lumen $[6,12,15]$. These include the presence of specific protease inhibitors such as aprotinin or soybean trypsin inhibitor together with a surface acting compound such as the sodium cholate which favours absorption by the enterocytes $[6,12]$. The nature of the insulin absorbed, either as an intact molecule or as fragmented peptides could not be defined. However, the peptides absorbed and transferred to the blood circulation retained potent biological activity and thus were able to induce significant lowering of blood glucose which constitutes our main objective. They were also recognized by the anti-insulin antibody 
either in the radioimmunoassay or in the immunocytochemical techniques. Thus, in spite of the presence of proteases in the lumen of the digestive tract, our studies have demonstrated that under the particular conditions used, the enterocytes are able to transfer significant amounts of biologically active insulin to the internal milieu.

The morphological examination of the different tissues at the end of the 6-h experiments has shown that little damage if any, was induced in the tissue by the introduction of the insulin solution and that the integrity of the intestinal wall was maintained. This is particularly important since sodium cholate and protease inhibitors were present along with the insulin solution. The retention of the integrity of the epithelial wall is crucial for the significance of these experiments since artefactual gaps in the intestinal wall, such as enlargement of the junctional complexes between adjacent cells or damaged cells, could contribute to the indiscriminate passage of any substance present in the intestinal lumen along with the insulin. The morphological study has further defined the pathway taken by insulin across the intestinal wall. Electron microscopic immunocytochemistry has demonstrated that the insulin present in the lumen of the intestinal tract is absorbed through the endosomal compartment of the epithelial cells rather than passing between cells through the junctional complexes. However, since the procedure used is considered to be a threshold technique in terms of sensitivity, we cannot rule out that minute amounts of insulin could pass through the junctions escaping our detection. On the other hand, compared to the amounts detected inside the cells, insulin creeping through the junctions must be minimal particularly since the junctional complexes remained tight. Furthermore, no expansion of the lateral intercellular space at the level of the occluding junctions, such as those reported by Madara and Pappenheimer [27], was observed and no significant change of the terminal web cytoskeletal elements was detected.

Shortly after introduction of insulin into the lumen of the duodenum or of the colon, the peptide detected by the immunolabelling, appeared to be associated with the luminal plasma membrane of the enterocytes either along the microvilli or at their base. This absorption of insulin to the apical plasma membrane may take place through binding to a specific receptor. Such an insulin receptor has been described in intestinal enterocytes although its presence in the apical membrane remains controversial [28-30]. Following adsorption to the membrane of the cells, insulin is internalized through deep invaginations of the luminal plasma membrane and vesical structures which are known to belong to the endosomal compartment. After 5 and $10 \mathrm{~min}$, the lateral plasma membrane was labelled as well as large extracellular pockets delineated by the lateral membranes of adjacent cells. This indicates that insulin is transferred to the lateral membranes and concentrated in these pocket structures prior to release into the interstitial space. The role of such an extracellular compartment for the handling and the release of absorbed material is extremely interesting deserving further investigation. The morphological detection of insulin in these "pockets" indicates its concentration in these sites but their functional properties remain to be determined. In the intracellular compartments on the other hand, the Golgi apparatus and associated vesicles were specifically labelled by few gold particles. Other structures such as mitochondria and nuclei were however not labelled. Because of results obtained in control experiments, the few gold particles present in these compartments were considered as background staining. The number of lysosomes remained small, suggesting that no cellular stress was induced, and these did not display any significant labelling. The results obtained thus appear to support the hypothesis of a transcytotic transport of insulin through the endosomal compartment from the luminal side to the basolateral one with a subsequent discharge in the intestinal interstitial space. From this, passage through the capillary endothelium takes place easily through plasmalemmal vesicles, fenestrations, or both, as we have demonstrated in Figure 9 and as reported previously in the pancreas [31].

Enteral absorption of biological insulin is the key step for the development of an oral preparation for use in the treatment of diabetic patients. In the present and previous studies [15] we have demonstrated that insulin administered to various sites of the small and large intestine, under particular well-defined conditions, is absorbed by similar mechanisms, transferred to the blood circulation and induces significant lowering of blood glucose levels. In the present study we demonstrated that similar insulin absorption takes place in normal and diabetic animals. These results have already opened the possibility for the clinical use of an oral preparation of insulin [32].

Acknowledgements. The authors would like to thank Doctors E. Rasio (Notre-Dame Hospital, Montreal, Quebec, Canada) and E.Levy (Ste-Justine Hospital, Montreal, Quebec, Canada) for their help in performing insulin radio-immunoassays as well as F. Kan (Université de Montréal, Montreal, Quebec, Canada) for the production of the freeze-fracture replicas and S. Ekmekjian from Connaught Novo Ltd (Lachine, Quebec, Canada) for generously supplying us with the insulin. This work was supported by grants from the Medical Research Council of Canada, the Université de Montréal, School of Medicine and from Neot Varod, Israel. Dr. E. Ziv was a Visiting Professor to the Université de Montréal from the Fonds de la Recherche en Santé du Québec.

\section{References}

1. Hirai S, Ikenaga T, Matasuzawa T (1978) Nasal absorption of insulin in dogs. Diabetes 27: 296-299

2. Salzman R, Manson JE, Griffing GT et al. (1985) Intranasal aerosolized insulin mixed meal studies and long-term use in type I diabetes. N Engl J Med 312: 1078-1084 
3. Gordon GS, Moses AC, Silver RD, Flier JS, Carey MC (1985) Nasal absorption of insulin: enhancement by hydrophobic bile salts. Proc Natl Acad Sci USA 82: 7419-7423

4. Ichikawa K, Ohata I, Mitomi M, Kawamura S, Maeno H, Kawata $H$ (1980) Rectal absorption of insulin suppositories in rabbits. J Pharm Pharmacol 32: 314-318

5. Ziv E, Kidron M, Berry EM, Bar-On H (1981) Bile salts promote the absorption of insulin from the rat colon. Life Sci 29: 803-809

6. Ziv E, Kleinman Y, Bar-On H, Kidron M (1984) Treatment of diabetic rats with enteral insulin. In: Shafrir E, Renold AE (eds) Lessons from animal diabetes. John Libbey, London, pp 642-647

7. Ritschel WA, Ritschel GE (1984) Rectal administration of insulin. Methods Find Exp Clin Pharmacol 6: 513-529

8. Raz I, Bar-On H, Kidron M, Ziv E (1984) Rectal administration of insulin. Isr J Med Sci 20: 173-175

9. Nishihata T, Rytting JH, Kamada A, Higuchi T (1981) Enhanced intestinal absorption of insulin in rats in the presence of sodium 5-methoxy-salicylate. Diabetes 30: 1065-1067

10. Bar-On H, Berry EM, Eldor A, Kidron M, Lichtenberg D, Ziv E (1981) Enteral administration of insulin in the rat. $\mathrm{Br} \mathrm{J}$ Pharmacol 73: 21-24

11. Kidron M, Bar-On H, Berry EM, Ziv E (1982) The absorption of insulin from various regions of the rat intestine. Life Sci 31: 2837-2841

12. Ziv E, Lior O, Kidron M (1987) Absorption of protein via the intestinal wall: a quantitative model. Biochem Pharmacol 36: 1035-1039

13. Damge C, Michel C, Aprahamian M, Couvreur P (1988) New approach for oral administration of insulin with polyalkylcyahoacrylate manocapsules as drug carrier. Diabetes 37 : 246-251

14. Kidron M, Krausz MM, Raz I, Bar-On H, Ziv E (1989) The absorption of insulin from the intestine in dogs. Tenside Surf Det 26: 352-354

15. Bendayan M, Ziv E, Ben-Sasson R, Bar-On H, Kidron M (1990) Morpho-cytochemical and biochemical evidence for insulin absorption by the rat ileal epithelium. Diabetologia 33: 197-204

16. Cho YW, Flynn M (1989) Oral delivery of insulin. Lancet II: 1518-1519

17. Murlin JR, Sutter CC, Allen RS, Piper HA (1924) Some favorable effects from the alimentary administration of insulin. Endocrinology 8: 331-339

18. Salen E (1924) Einige Versuche mit peroraler Darreichung von Insulin. Acta Med Scand 60:74-87
19. Murlin JR, Young LE, Phillips WA (1937) New results on the absorption of insulin from the alimentary tract. Science 86 : 412

20. Murlin JR, Gibbs CBF, Romansky MJ, Steinhausen TB, Truax FL (1940) Effectiveness or per-oral insulin in human diabetes. J Clin Invest 19: 709-722

21. Hanzlik PJ, Cutting WC (1941) Agents promoting gastrointestinal absorption of insulin. Endocrinology 28: 368-374

22. Bendayan M (1984) Protein A-gold electron microscopic immuno-cytochemistry: methods, applications and limitations. J Electron Microsc Tech 1:243-270

23. Bendayan M (1989) Protein A-gold and protein G-gold postembedding immunoelectron microscopy. In: Hayat MA (ed) Colloidal gold cytochemistry techniques and applications. Academic Press, New York, pp 33-94

24. Willison JHM, Rowe AJ (1980) Replica, shadowing and freeze-etching techniques. In: Glauert AM (ed) Practical methods in electron microscopy Vol 8. North-Holland Pub Co, New York, pp 171-276

25. Ghitescu L, Bendayan M (1990) Immunolabelling efficiency of protein A-gold complexes. J Histochem Cytochem 38: $1523-1530$

26. Rodier-Bruant C, Vaxman F, Lambert A et al. (1991) Etude de l'absorption intestinal de l'insuline chez le chien grâce à une nouvelle capsule de largage télémétrique. Gastroenterol Clin Biol 15: 187-193

27. Madara JL, Pappenheimer JR (1987) Structural basis for physiological regulation of paracellular pathways in intestinal epithelia. J Membrane Biol 100: 149-164

28. Bergeron JJM, Rachubinski R, Searle N, Borts D, Sikstrom $\mathrm{R}$, Posner BI (1980) Polypeptide hormone receptors, in vivo: demonstration of insulin binding to adrenal gland and gastrointestinal epithelium by quantitative radioautography. $J$ Histochem Cytochem 28: 824-835

29. Pillion DF, Ganapathy V, Leibach FH (1985) Identification of insulin receptors on the mucosal surface of colon epithelial cells. J Biol Chem 260: 5244-5247

30. Fernandez-Moreno MD, Serrano-Rios M, Prieto JC (1987) Identification of insulin receptors in epithelial cells from duodenum, jejunum, ileum, caecum, colon and rectum in the rat. Diabete Metab 13: 135-139

31. Bendayan M (1993) Pathway of insulin in pancreatic tissue on its release by the B-cell. Am J Physiol 264: G187-G194

32. Ziv E, Kidron M, Raz I et al. (1991) The treatment of diabetes by oral delivery of insulin. Diabetes 40: 341A (Abstract) 